\title{
perifèria
}

Número 18(2), diciembre 2013

http://revistes.uab.cat/periferia

\section{La movilidad mapuche: tensiones entre patrones culturales e imposiciones estatales}

\author{
Sabine Kradolfer - Université de Lausanne (Suiza) ${ }^{1}$
}

\section{Resumen}

A través de los siglos, los Mapuche de la Patagonia argentina experimentaron diferentes patrones de movilidad ligados al cuidado y a la venta de ganado. Después de su sometimiento a finales del siglo 19, el Estado argentino les impuso sus lugares de asentamiento quebrando así la continuidad ocupacional con sus territorios "tradicionales". Así es que la movilidad poblacional actual resulta tanto de elecciones por los grupos mapuche como de imposiciones por parte del Estado.

\begin{abstract}
Over the last centuries, the Mapuche of Argentine Patagonia have experienced different mobility patterns linked to the care and and sale of animals. After their subjugation at the end of the $19^{\text {th }}$ century, the Argentine State imposed on them the places where they had to settle, thus breaking the occupational continuity with their "traditional" territories. Hence, the current population mobility results both from the choices of the Mapuche groups and from obligations imposed by the State.
\end{abstract}

Los Mapuche son un pueblo indígena de alrededor de un millón de personas ${ }^{2}$, ahora dispersas sobre casi toda la extensión de Chile y Argentina con una fuerte concentración en las zonas urbanas, quienes ocupaban históricamente un territorio ubicado en el sur de ambos países donde diferentes patrones de asentamiento dibujaron a través del tiempo diversos modelos de movilidad y/o fijezas en el territorio (Ramos y Kradolfer 2011). Me interesaré aquí en particular por los Mapuche que pueblan la Patagonia argentina para resaltar como, a través del tiempo, utilizaron diferentes patrones de movilidad (por elección o por imposición)

\footnotetext{
1 Enviar correspondencia

a: Sabine

Kradolfer,

Kradolfer.Sabine@gmail.com

2 Resulta particularmente difícil indicar una cifra exacta ya que las organizaciones indígenas y las oficinas de estadísticas y censos de ambos países discrepan en sus cálculos. Para una discusión detallada sobre la inclusión de la variable étnica en los censos de población latino-americanos, véase Angosto Ferrández y Kradolfer (2012).
} 


\section{perifèria}

Número 18(2), diciembre 2013

http://revistes.uab.cat/periferia

y se han desplazado a lo largo de un inmenso territorio que se extiende desde las costas Atlánticas hacia la Cordillera de los Andes, Cordillera que marca la frontera actual con el Estado chileno. En el pasado, lejos de ser entendida como una barrera (y por ende una limitación del movimiento) la Cordillera y sus diferentes pisos ecológicos estaban ocupados en la primavera y en el verano por los Mapuche y sus rebaños. Los numerosos pasos de baja altura que se encuentran en la Patagonia permitían además los intercambios de bienes y el movimiento de los grupos humanos de un lado a otra de esta cadena montañosa.

Si hoy día, los patrones de movilidad se limitan al nomadismo trashumante y a las migraciones entre el campo y las ciudades, en épocas anteriores, los Mapuche solían intercambiar ganado mayor moviéndose desde el Pacifico hasta el Atlántico y alimentando amplios circuitos comerciales. Esta "edad de oro" de la sociedad mapuche fue abruptamente interrumpida por la conquista militar de los territorios indígenas por parte de los Estados argentino y chileno durante el último cuarto del siglo XIX. En este artículo me interesa mostrar cómo estos tres momentos históricos: antes, durante y después del sometimiento de los Mapuche, presentan patrones de movilidad muy diferentes pero representativos de cada época.

\section{La importancia de pertenecer a un lugar}

En el año 2006, en Argentina, fue promulgada la ley Nacional 26,160 de "Emergencia y Regularización de la Propiedad Comunitaria Indígena" que establece, "(...) la emergencia en materia de posesión y propiedad de tierras que tradicionalmente ocupan las comunidades indígenas originarias del país". Dicha ley, a pesar de no haberse cumplido hasta el día de hoy con su propósito, llevó a muchas discusiones, disputas y peleas entre defensores de los pueblos indígenas y adeptos de una visión de la población argentina como homogénea. En el caso Mapuche, y por lo que nos interesa en relación con la movilidad, cabe destacar el cuestionamiento por parte de ciertos sectores sociales conservadores de la 


\section{perifèria}

Número 18(2), diciembre 2013

http://revistes.uab.cat/periferia

ocupación tradicional de los territorios hoy reclamados por las comunidades ${ }^{3}$ (véase por ejemplo Trentini et al. 2010).

El concepto de "ocupación tradicional" es retomado del derecho internacional en materia de pueblos indígenas y figura dentro del Convenio 169 de la "Organización internacional del trabajo sobre pueblos indígenas y tribales" de 1989 y de la "Declaración de las Naciones Unidas sobre los derechos de los pueblos indígenas" de 2007. En la Patagonia argentina este concepto toma matices particulares ya que las poblaciones mapuche y mapuche-tehuelche siempre estuvieron en movimiento (por sus patrones culturales propios o por haber sido corridos por el ejército nacional a finales del siglo XIX) sobre todo el territorio que ocupaban desde la Provincia de Buenos Aires hasta el sur del continente (Fig. 2). Por ende, estos movimientos cuestionan los derechos sobre los territorios que reivindican ciertas comunidades porque no siempre se puede comprobar la "ocupación tradicional" stricto sensu. Veamos por qué.

\section{Los siglos XVIII y XIX: la edad de oro y de auge de la sociedad mapuche}

A partir del siglo XVIII, se desarrollan importantes circuitos comerciales entre los territorios bajo control mapuche que se encontraban al este y al oeste de la Cordillera de los Andes e iban desde el Pacífico hasta el Atlántico. Mandrini (1985) identifica dos circuitos económicos indígenas bien articulados que van formando un sistema complejo entre las poblaciones que viven del comercio del ganado. El primero, llamado "circuito del ganado", se refiere al traslado de grandes cantidades de bovinos y caballos desde las pampas argentinas hacia la frontera mapuchechilena sobre el Río Bíobío para abastecer la importante demanda de animales, cuero y/o carne por parte de la población criolla (véase fig. 2). El segundo, llamado "circuito comunal", alude a las actividades económicas necesarias al autoconsumo dentro de las tolderías (caza, horticultura, recolección, cría de animales, etc.).

\footnotetext{
${ }^{3}$ Como lo indica su nombre, esta ley no se dirige a los pobladores indígenas dispersos en el territorio argentino, sino únicamente a las comunidades.
} 


\section{perifèria}

Número 18(2), diciembre 2013

http://revistes.uab.cat/periferia

El "circuito del ganado", que nos interesa aquí, muestra un patrón de movilidad complejo sobre largas distancias (más de mil kilómetros) y creador de mucha riqueza para los grupos mapuches quienes son los mayores vendedores de ganado y caballos en la zona. Esta imagen contrasta fuertemente con los sistemas de autosubsistencia en los cuales otros grupos desarrollan sus actividades en la misma época. Cabe notar que hasta el día de hoy, la palabra cullin (en mapudungun, la lengua mapuche) nombra tanto al ganado como al dinero, prueba del lugar central ocupado por el primero en los intercambios comerciales. Pero a medida que la frontera agro-pecuaria avanza sobre los territorios indígenas de las Pampas en el siglo XIX, van disminuyendo las reservas de ganado disponible para los Mapuche, quienes empiezan a extraer animales de las grandes propiedades privadas (estancias) instaladas sobre la línea de frontera. En aquella época, la frontera sur de la Argentina no llegaba ni al límite actual de las provincias de Buenos Aires y de Mendoza, y pasaba al sur de las provincias de Córdoba y de San Luís (Fig. 2), dejando gran parte de las pampas húmedas en mano de los Mapuche.

\section{La "perdición" y los desplazamientos forzados}

Para proteger las estancias y terminar con las incursiones indígenas para la apropiación de ganado mayor, el Estado argentino decide la conquista de los territorios libres del sur del continente. Estas guerras son recordadas por los libros de historia como la "Conquista del Desierto" mientras para los Mapuche significaron "la Perdición" o "la Época de la Perdición". Entre 1879 y 1885, varias campañas militares empujaron la línea de frontera entre la República Argentina y la Nación mapuche cada vez más al sur, desplazando y corriendo a una importante población indígena. Si existió durante un tiempo una posibilidad de huir del otro lado de la Cordillera de los Andes, rápidamente el ejército chileno también empezó a anexar militarmente a los territorios mapuche en un proceso llamado "Pacificación

\footnotetext{
${ }^{4}$ Sobre la denominación de "desierto" y la funcionalidad de aquella denominación para su anexión al territorio nacional argentina, véase Kradolfer y Navarro Floria (2006).
} 


\section{perifèria}

Número 18(2), diciembre 2013

http://revistes.uab.cat/periferia

de la Araucanía". Del lado argentino, la rendición de los últimos caciques, en 1885, marcó el final de este momento particularmente cruento para el pueblo mapuche que sufrió una desarticulación casi total de su organización social, política y militar.

Durante y después de las campañas militares, muchos de los indígenas que no murieron en enfrentamientos armados o en los ataques del ejército argentino contra las tolderías y los asentamientos poblacionales donde se encontraban las mujeres y los niños, fueron deportados como prisioneros en campos de concentración para ser después enviados a diferentes partes del país. Las familias fueron separadas y mientras los hombres tenían que trabajar de manera forzada en la construcción de los ferrocarriles, las plantaciones de caña de azúcar, las estancias del centro del país o enrolados en el ejército o las fuerzas navales, las mujeres y los niños fueron distribuidos entre familias argentinas quienes necesitaban sirvientes para el trabajo doméstico (Varela and Font 1995: 178-179). Según varios historiadores, el daño producido entre la sociedad mapuche debe ser considerado como un genocidio (Delrio 2005, Lenton 2010, Delrio et al. 2010, Navarro Floria 1999: 104-106).

\section{Las políticas de reasentamiento: fijando los Mapuche en el territorio}

Después de la Conquista del Desierto, las poblaciones indígenas que lograron sobrevivir y escapar al exilio quedaron en la Patagonia como pequeños grupos aislados y errantes, privados de sus territorios y medios de subsistencia, testigos de la destrucción sistemática de su sociedad. Destrucción sistemática porque además de la muerte y deportación de parte de la población, los contingentes de sobrevivientes conocieron una desaparición simbólica al tener que abandonar su modo de vida comunitario, su cultura, su lengua, etc. para insertase en la sociedad nacional argentina considerada como "civilizada" y que reenviaba las culturas indígenas a la "barbarie".

\footnotetext{
${ }^{5}$ Araucanos es el nombre dado por los conquistadores españoles a los Mapuche; por Araucanía, se entiende en Chile, el territorio ocupado por las poblaciones mapuche.
} 


\section{perifèria}

Número 18(2), diciembre 2013

http://revistes.uab.cat/periferia

Poco a poco, las familias se fueron reagrupando por voluntad propia o por aquella del Estado, el cual quería reasentar a las familias de prisioneros deportados en "reservas". Estas últimas eran vistas como una etapa intermediaria para atraer los indígenas a la vida "civilizada" y enseñarles modos de vida más adecuados a los ideales progresistas del final del siglo XIX. Así es como los nuevos lugares de asentamiento de los grupos mapuche fueron determinados por las autoridades argentinas. Las tierras que ocuparon a partir de entonces son, en general, tierras fiscales (públicas) y los Mapuche tienen que organizarse en acuerdo con las leyes impuestas por parte del Estado, quien legisla sobre el devenir de lo que calificó, según las épocas y los lugares, como "reservas", "agrupaciones", "colonias", "tribus" o "comunidades" indígenas ${ }^{6}$. En este proceso, no sólo pierden sus territorios, sino también su historia propia que pasa a ser parte o del pasado, o de un presente que se articula, o mejor dicho, es infeudada a "la" historia oficial de un Estado, quien durante más de un siglo, rechaza su diversidad interna.

\section{Criando animales en la Patagonia: moviendo la fijeza}

Si las mejores tierras se encuentran en la pampa húmeda y a orillas de los grandes ríos, los territorios entregados a los indígenas están situados en las zonas más áridas y son poco adecuados para la agricultura o la ganadería, dejando a los lof en situaciones económicas muy precarias hasta el día de hoy. Por ejemplo, los familiares y descendientes de los grandes caciques Calfucurá y Namuncurá que poblaban la región de las Salinas Grandes (actualmente en el sudoeste de la provincia de Buenos Aires y del sudeste de la provincia de La Pampa), antes de 1879, fueron relocalizados en el sur de la provincia de Neuquén en el paraje San Ignacio a más de mil kilómetros de distancia. Lo mismo ocurrió con la gente del cacique Sayhueque, quien ocupaba un valle llamado "País de las Manzanas" cercano al actual lugar de asentamiento del lof Namuncurá y está ahora dividida entre diferentes lugares, sea en la provincia de Neuquén (en el paraje de Atreuco al pie de la Cordillera de los Andes: comunidad Sayhueque), en la meseta chubutense

\footnotetext{
${ }^{6}$ La palabra en mapudungun utilizada actualmente para nombrar estas estructuras es lof.
} 


\section{perifèria}

Número 18(2), diciembre 2013

http://revistes.uab.cat/periferia

(comunidad mapuche-tehuelche Valentín Sayhueque) o en otras localidades donde se encuentran personas mapuche que llevan el apellido Sayhueque pero no se hallan reunidas en comunidades o lof.

El asentamiento de los lof en las zonas más inhóspitas de la Patagonia obliga los Mapuche - al igual de lo que hacen otros pequeños productores de ganado lanar y ovino $^{7}$ - a practicar un modo de vida trashumante. Este permite la recuperación de los pastos durante los meses en los cuales los rebaños se encuentran en otros lugares. Así es que durante el verano, las familias o parte de ellas se desplaza sobre decenas de kilómetros con sus animales desde las zonas bajas (Ilamadas "invernadas") hacia los valles cordilleranos donde se encuentran las "veranadas", unas viviendas precarias donde pasan el verano con sus animales. Ciertos grupos hacen una etapa adicional de unas semanas en el camino en lugares intermedios llamados las "primaveras" ya que suelen parar allá en tiempo de primavera.

\section{La paradoja actual: tener derechos sobre un territorio que es, y no es, ancestral}

La complejidad de los patrones de movilidad de los grupos mapuche a través del tiempo complica hoy en día los reclamos territoriales de los lof. Si volcamos la mirada hacia los territorios "tradicionalmente" ocupados, o sea aquellos anteriores a la Conquista del Desierto, vemos que muchas veces son muy distantes de los lugares actuales de asentamiento, que no fueron elegidos por las comunidades pero son el resultado de un proceso histórico de despojo territorial por parte del Estado nacional argentino y de posterior reubicación. En este contexto, cabe preguntarse sobre cuáles son las demandas más legítimas en relación con lo que provee el derecho internacional sobre pueblos indígenas:

\footnotetext{
7 Si hasta la Conquista del Desierto los Mapuche fueron criadores de ganado mayor, sus condiciones actuales de vida los llevan a criar principalmente ganado menor.
} 


\section{perifèria}

Número 18(2), diciembre 2013

http://revistes.uab.cat/periferia

\section{Convenio 169 de la Organización internacional del trabajo sobre pueblos indígenas y tribales (1989)}

Artículo 14. 1. Deberá reconocerse a los pueblos interesados el derecho de propiedad y de posesión sobre las tierras que tradicionalmente ocupan.

\section{Declaración de las Naciones Unidas sobre los derechos de los pueblos indígenas (2007)}

Artículo 26

1. Los pueblos indígenas tienen derecho a las tierras, territorios y recursos que tradicionalmente han poseído, ocupado o de otra forma utilizado o adquirido.

2. Los pueblos indígenas tienen derecho a poseer, utilizar, desarrollar y controlar las tierras, territorios y recursos que poseen en razón de la propiedad tradicional u otra forma tradicional de ocupación o utilización, así como aquellos que hayan adquirido de otra forma.

3. Los Estados asegurarán el reconocimiento y protección jurídicos de esas tierras, territorios y recursos. Dicho reconocimiento respetará debidamente las costumbres, las tradiciones y los sistemas de tenencia de la tierra de los pueblos indígenas de que se trate.

Si los territorios tradicionalmente ocupados por grupos en movimiento son extensos y fueron cambiando a lo largo del tiempo por elección propia y por imposición del Estado ¿Cuáles son los territorios que corresponden a las comunidades mapuche? ¿Serán aquellos que fueron otorgados en ocupación precaria a los lof a lo largo del siglo XX? ¿Los que se refieren a tierras fiscales todavía libres de ocupantes donde grupos mapuche se instalan para desafiar al Estado y "recuperar el territorio ancestral" (entiéndase "toda la Patagonia") como es el caso de la comunidad de Ragiñ-có en las cercanías de las ciudad de Neuquén?

Benetton está cuestionando la ancestralidad de la ocupación de la comunidad de Santa Rosa Leleque en el juicio que los opone para la propiedad de un predio de 500 ha (Briones y Ramos 2005). Si bien es cierto que el siglo XIX, la ocupación de las tierras del Chubut no eran de mucho interés para grupos humanos que podían gozar de tierras mucho más fértiles y de un clima más temblado en las pampas, el reasentamiento posterior a la Conquista del Desierto en varios lugares inhóspitos 


\section{perifèria}

Número 18(2), diciembre 2013

http://revistes.uab.cat/periferia

de la actual provincia del Chubut ¿no le da derecho a los Mapuche a reclamar tierras sobre las cuales tal vez sólo transitaron o pararon durante poco tiempo, antes que la instalación de alambrados imposibilitara el movimiento fuera de la rutas oficiales en los años 1940-1950? Estas son preguntas que el Estado y las comunidades y organizaciones mapuche tendrán que resolver para posibilitar el debido acceso a la tierra y a los territorios que tanto las regulaciones internacionales como nacionales reconocen ahora para los pueblos indígenas.

\section{Bibliografía}

Angosto Ferrández, Luis Fernando y Kradolfer, Sabine (2012). Everlasting countdowns: race, ethnicity and national censuses in Latin American states. Newcastle: Cambridge Scholars Publishing.

Briones, Claudia y Ramos, Ana (2005). "Audiencias y contextos: la historia de 'Benetton contra los mapuches'". E-misférica, $\mathrm{n}^{\circ}$ 2.1, Disponible en: http://hemi.es.its.nyu.edu/journal/2_1/briones.html

Delrio, Walter (2005). Memorias de Expropiación. Sometimiento e incorporación indígena en la Patagonia (1872-1943). Buenos Aires: Editorial de la Universidad de Quilmes.

Delrio, Walter, Lenton, Diana Musante, Marcelo, Nagy, Mariano, Papazian, Alexis, y Pérez, Pilar (2010). "Discussing the indigenous genocide in Argentina: Past, present and consequences of Argentinean state policies toward native peoples". Genocide Studies and Prevention, vol. 5, no 2, pp.138-159.

Kradolfer, Sabine y Navarro Floria Pedro (2006). "De la difficulté d'entendre la voix de I'Autre quand elle remet en question un héros national". Carnets-de-bord (University de Genève), no 12, pp. 57-66. Disponible en: http://www.unige.ch/ses/socio/carnets-debord/revue/article.php?NoArt=123\&num $=12$ 


\section{perifèria}

Número 18(2), diciembre 2013

http://revistes.uab.cat/periferia

Lenton, Diana (2010). "Próceres genocidas: una indagación en el debate público sobre la figura de Julio A. Roca y la Campaña del Desierto" en Huffschmid A. (ed.), Topografías conflictivas. Memorias, Espacios y Ciudades en disputa, Instituto de Estudios Latinoamericanos, Freie Universität Berlin.

Navarro Floria, Pedro (1999). Historia de la Patagonia. Buenos Aires: Ciudad Argentina.

Mandrini, Raúl José (1985). "La agricultura indígena en la región pampeana y sus adyacencias (siglos XVIII y XIX)". Anuario del IEHS (Tandil), n 1, pp. 11-43.

Ramos, Ana, y Kradolfer, Sabine (2011). "Las memorias de ruta. Repensando los movimientos y las fijezas". Anuario americanista europeo, n 9, pp. 101-118. Disponible en:

http://www.red-redial.net/revista/anuario-americanistaeuropeo/article/viewFile/129/145

Trentini, F., Valverde, S., Radovich, J. C., Berón, M. A., \& Balazote, A. (2010). " Los nostálgicos del desierto": la cuestión mapuche en Argentina y el estigma en los medios. Cultura y Representaciones Sociales, vol. 4, no 8, pp. 186-212. Disponible en: http://www.ojs.unam.mx/index.php/crs/article/view/16480

Varela, Gladys \& Font, Luz María (1995). "Reemplazos y coincidencias en el poblamiento de Neuquén. La integración de un espacio criollo." Revista de Historia (Neuquén), nº 5, pp. 173-183. 


\section{perifèria}

Número 18(2), diciembre 2013

http://revistes.uab.cat/periferia

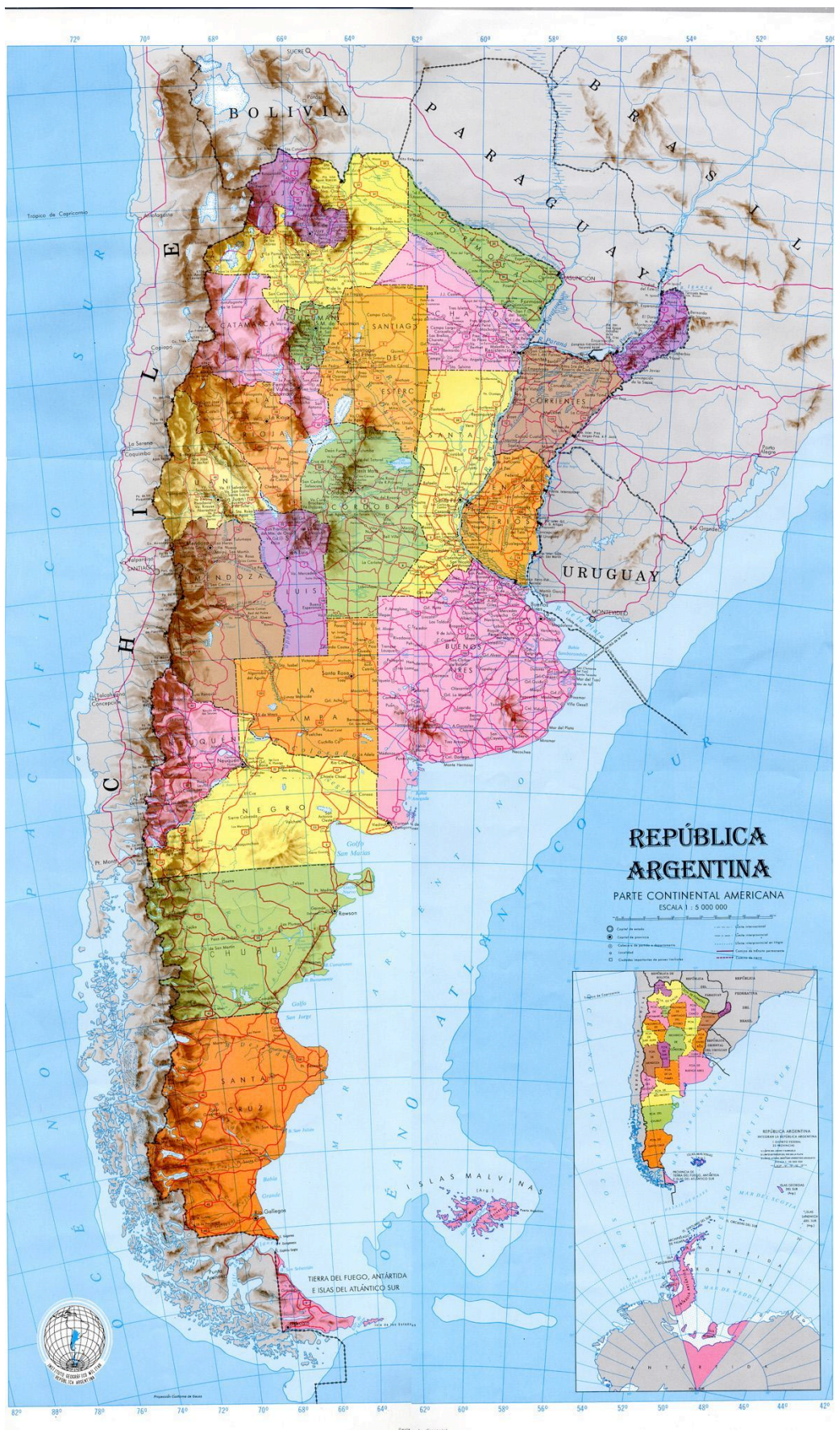

Fig. 1: Mapa de Argentina (ㄷ Instituto Geográfíco Militar) 


\section{perifèria}

Número 18(2), diciembre 2013

http://revistes.uab.cat/periferia

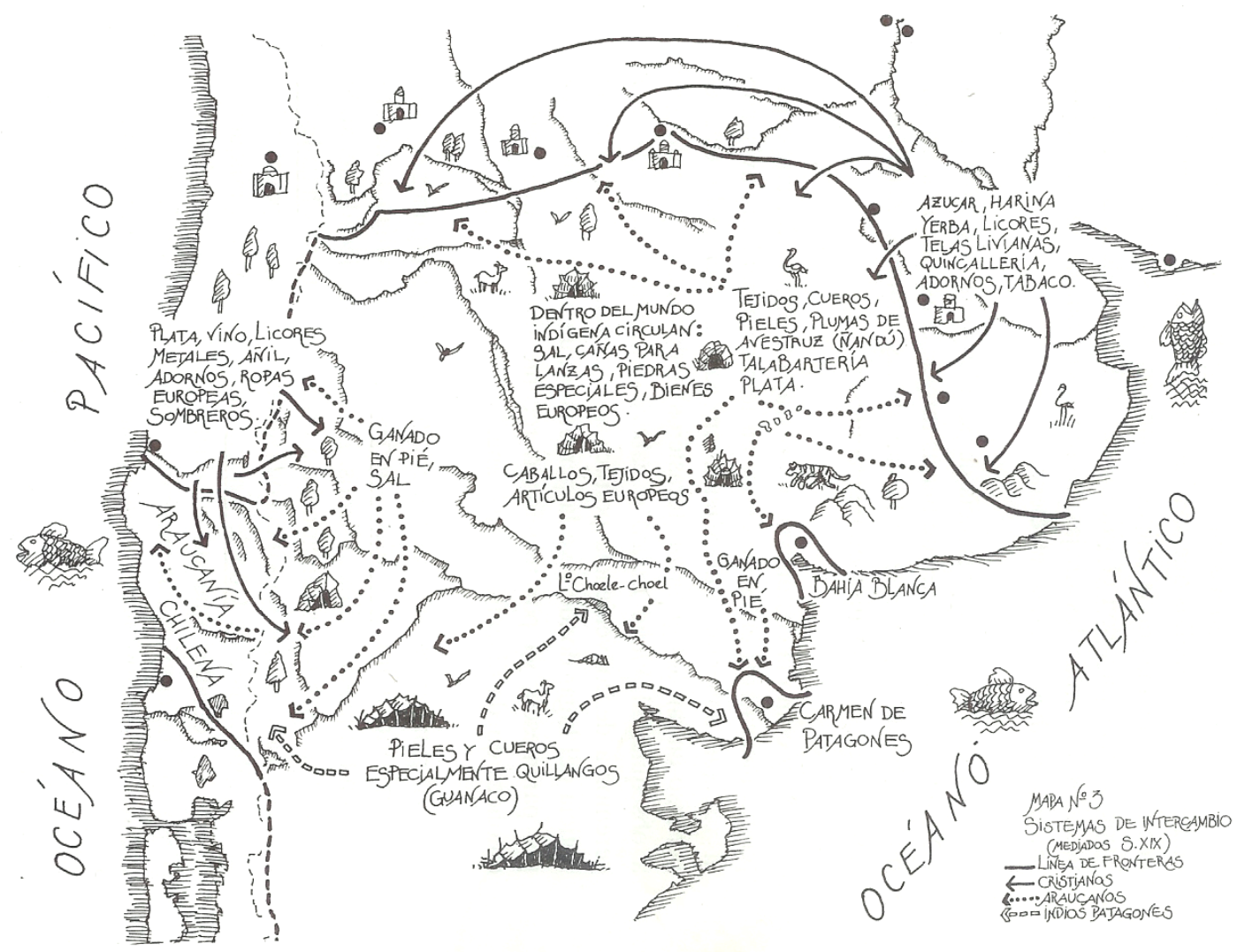

Fig. 2: Mapa del territorio indígena con indicación de los sistemas de intercambios y de las líneas de frontera entre 1852 y 1860 (@ Mandrini et Ortelli 1992: 113) 